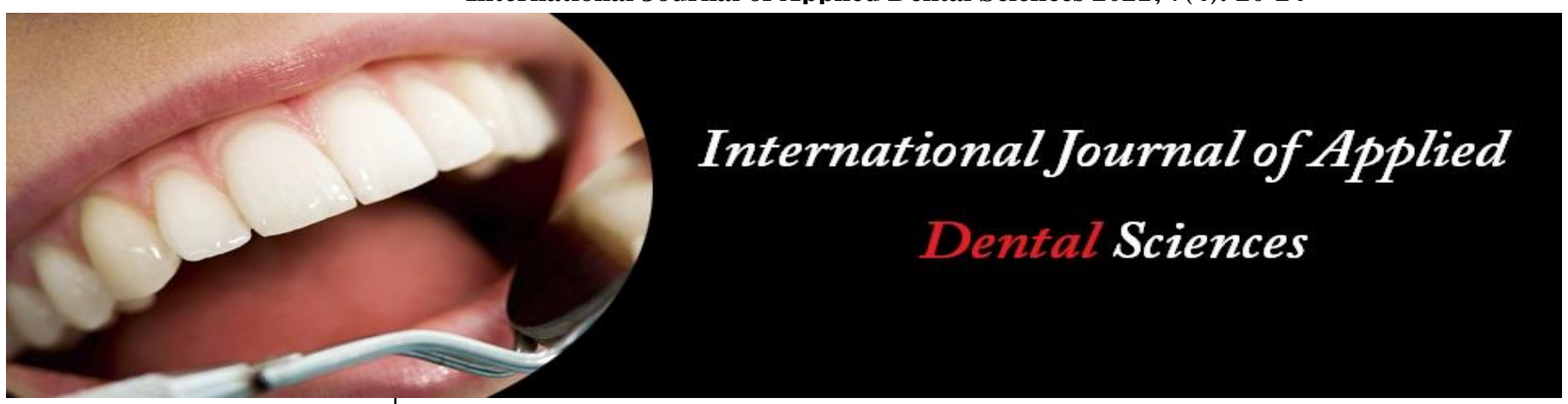

ISSN Print: 2394-7489

ISSN Online: 2394-7497

IJADS 2021; 7(4): 20-24

(C) 2021 IJADS

www.oraljournal.com

Received: 16-08-2021

Accepted: 18-09-2021

Astrid Aimee Huidobro-Guerrero Master in Sciences Student, Universidad Autonoma de Nuevo Leon, Facultad de Odontologia, Monterrey, Nuevo Leon, CP 64460 Mexico

Arturo Santoy-Lozano Professor, Universidad Autonoma de Nuevo Leon, Facultad de Odontologia, Monterrey, Nuevo Leon, CP 64460, Mexico

Fanny Lopez-Martinez Associate Professor, Universidad Autonoma de Nuevo Leon, Facultad de Odontologia, Monterrey, Nuevo Leon, CP 64460 Mexico

Rosa Alicia Garcia-Jau Professor, Universidad Autonoma de Sinaloa, Facultad de Odontologia, Culiacan, Sinaloa, Mexico

Aurea Elizabeth Valle-Urias Professor, Universidad Autonoma de Sinaloa, Facultad de

Odontologia, Culiacan, Sinaloa, Mexico

Sergio Eduardo Nakagoshi-Cepeda Professor, Universidad Autonoma de Nuevo Leon, Facultad de Odontologia, Monterrey, Nuevo Leon, CP 64460, Mexico

Juan Manuel Solis-Soto Professor, Universidad Autonoma de Nuevo Leon, Facultad de Odontologia, Monterrey, Nuevo Leon, CP 64460, Mexico
Corresponding Author: Juan Manuel Solis-Soto Professor, Universidad Autonoma de Nuevo Leon, Facultad de Odontologia, Monterrey, Nuevo Leon. CP 64460, Mexico

\section{Autologous platelet concentrates in regenerative endodontic treatment}

\author{
Astrid Aimee Huidobro-Guerrero, Arturo Santoy-Lozano, Fanny Lopez- \\ Martinez, Rosa Alicia Garcia-Jau, Aurea Elizabeth Valle-Urias, Sergio \\ Eduardo Nakagoshi-Cepeda and Juan Manuel Solis-Soto
}

DOI: https://doi.org/10.22271/oral.2021.v7.i4a.1347

\section{Abstract}

Introduction: Autologous platelet concentrates, have recently emerged as a possible tool to improve regenerative procedures in the medical field.

Objective: To analyze the literature on autologous platelet concentrates in regenerative endodontics, such as: Platelet Rich Plasma, Platelet Rich Fibrin, PRP/PRF Vs Blood Clot as a scaffold in regenerative endodontics.

Methodology: Using the keywords Regenerative Endodontic Treatment, Autologous Platelet Concentrates, Immature Teeth, Platelet-rich Fibrin, Platelet-rich Plasma, Revitalization Endodontics, the MEDLINE/PubMed and ScienceDirect databases were searched, with emphasis on the last 5 years. It was evaluated with the PRISMA and AMSTAR-2 guidelines.

Results: Platelet-rich plasma releases growth factors during the first hours after placement and induction of mesenchymal stem cells. Platelet Rich Fibrin is a second-generation platelet concentrate that releases growth factors more slowly, forming a network that traps leukocytes and platelets, liquid platelet rich fibrin has a higher concentration of leukocytes, which enhances immune defense in LPS-induced inflammation. Compared to blood clot, PRP and PRF show improved healing results, reducing infection and inflammation.

Conclusion: The use of autologous platelet concentrates presents a more controlled scaffold in regenerative endodontics, with successful results, such as periapical healing, root thickening and apical closure.

Keywords: regenerative endodontic treatment, immature tooth, autologous plasma concentrates, platelet rich fibrin, platelet rich plasma

\section{Introduction}

Regenerative endodontic treatment is a new option for immature permanent teeth with pulp necrosis, which eliminates clinical symptoms and further root development ${ }^{[1]}$. It aims to regenerate damaged/necrotic pulp-dentin complex tissues, such as dentin, pulp tissue and root structures, to restore pulpal functions ${ }^{[2]}$, depends on two factors: disinfection and stem cellmediated processes that promote root development ${ }^{[3]}$.

Cell-targeting approaches to engineer dental pulp rely on the recruitment of resident stem cells by endogenous dentin-derived growth factors, which induce cell migration to a custom-made scaffold, as well as cell proliferation and differentiation ${ }^{[4]}$. The main sources of stem cells in regenerative endodontic treatment are periapical tissues, and the main sources of growth factors are intra-canal blood clot, platelet-rich plasma and properly EDTA-conditioned dentin surfaces; in most cases, the scaffolds are intra-canal blood clot or the patient's own plateletrich plasma ${ }^{[5]}$. The use of blood clot, as a scaffold system in regenerative endodontic treatment has been questioned as it is likely to promote healing rather than controlled pulp regeneration1, therefore, a more controlled scaffold system that promotes pulp-like tissue and odontoblast cell differentiation is needed ${ }^{[6]}$.

Autologous platelet concentrates have recently emerged as a potential tool to improve regeneration procedures in the medical field ${ }^{[7]}$. Platelet-rich plasma and platelet-rich fibrin have been used as scaffolds for regenerative endodontic treatment, due to their rich content of 
platelets and important growth factors, which give variable results ${ }^{[8]}$.

Regenerative endodontic treatment, has been suggested as an option in permanent dental pieces with immature apices, from scaffolds with growth factors, there are several studies that currently report the use of autologous platelet concentrates, it is necessary to analyze, the treatment protocols, as well as the success rates reported in current literature, compared to traditional treatments, therefore, the objective of this study is to analyze the literature about autologous platelet concentrates in regenerative endodontics, such as: Platelet Rich Plasma, Platelet Rich Fibrin, PRP/PRF Vs Blood Clot as a scaffold in regenerative endodontics.

\section{Materials and Methods}

Articles on the subject published through the PubMed, SCOPUS and Google Scholar databases were analyzed, with emphasis on the last 5 years. The quality of the articles was evaluated using PRISMA guidelines, i.e., identification, review, choice and inclusion. The quality of the reviews was assessed using the measurement tool for evaluating systematic reviews (AMSTAR-2).

The search was performed using Boolean logical operators AND, OR and NOT.

It was constructed with the words "Regenerative endodontics", "Autologous platelet concentrates", "Platelet Rich Plasma", "Platelet Rich Fibrin". The keywords were used individually, as well as each of them related to each other. Initially, the titles of all the articles were selected, the abstract of each one was evaluated, and the articles were chosen for a complete reading review.

\section{Results and Discussion \\ 3.1 Platelet Rich Plasma (PRP)}

Platelet-rich plasma is widely applied as a bioactive scaffold in cell therapy and tissue engineering ${ }^{[2]}$. PRP is the processed liquid fraction of autologous peripheral blood with a platelet concentration above baseline ${ }^{[9]}$, obtained by platelet activation and fibrinogen polymerization ${ }^{[10]}$. During the preparation of platelet-rich plasma, the centrifuged blood is mixed with thrombin and calcium chloride to induce massive activation of concentrated platelets and gelation of the preparation ${ }^{[11]}$.

Platelet-rich plasma releases growth factors rapidly within 7 to 14 hours, which then decreases ${ }^{[12]}$. Platelet activation leads to their degranulation and in situ release of key growth factors involved in tissue regeneration, including PDGF, TGF-b, IGF, VEGF and EGF ${ }^{[13]}$. The use of platelet-rich plasma as a scaffold could increase hard tissue formation in revascularization procedures ${ }^{[14]}$. Protocols for collecting PRP involve the use of anticoagulants and high g-forces to selectively separate blood cells based on density ${ }^{[15]}$. PRP releases significantly more growth factors compared to fibrinrich plasma (FRP) during the first 15 to $60 \mathrm{~min}$ after clot formation, whereas FRP shows a continuous and steady release of a modest amount of growth factors over a 10-day period ${ }^{[16]}$. These high concentrations of bioactive molecules released by PRP could be responsible for the apparent beneficial effects on PRF, at least in the short term ${ }^{[17]}$.

\subsubsection{Effect on Dental Pulp Cells}

Platelet Rich Plasma has increased concentrations of growth factors that can attract stem cells present in apical tissues (vital pulp cells, periodontal ligament, apical dental papilla, bone marrow) and even from periapical lesions ${ }^{[18]}$. PRP contains a 6- to 8-fold increase in blood-derived growth factors that influence cell growth, morphogenesis and differentiation ${ }^{[19]}$. It promotes mesenchymal stem cell/stromal stem cell migration and wound healing process ${ }^{[20]}$.

Platelet Rich Plasma is a platelet concentrate obtained by centrifugation of autologous peripheral blood, has been used as a scaffold in regenerative endodontic treatment, due to the release of growth factors during the first hours of its placement, and the induction of migration and differentiation of mesenchymal stem cells.

\subsection{Platelet Rich Fibrin (PRF)}

Platelet Rich Fibrin builds on PRP by preserving growth factors in a fibrin matrix and can exert its effects days or weeks after surgery [21]. Being the second generation of platelet concentrates, platelet-rich fibrin (PRF) has many advantages over PRP, first, the preparation of PRF excludes the addition of exogenous agents such as thrombin, second, PRF is an organized fibrin gel that traps platelets and leukocytes, releasing various growth factors in the long term and third, immune cells and cytokines in a PRF clot could also act against infection ${ }^{[22]}$.

It has many advantages over Platelet Rich Plasma, it does not require the addition of exogenous agents, such as thrombin, it forms an organized fibrin network in which platelets and leukocytes are trapped ${ }^{[23]}$. It is formed during a gradual polymerization protocol that incorporates a higher concentration of cytokines in fibrins, therefore, the growth factors entangled in these fibers are released more slowly between 7 and 14 days ${ }^{[12]}$. PRF is a matrix that contains all the molecular and cellular elements that allow optimal healing. Polymerization of Platelet Rich Fibrin involves only endogenous components, making it a fibrin network more suitable for storage of cytokines and growth factors and for cell migration ${ }^{[24]}$. Platelet-rich fibrin clots produced using high centrifugation speed tend to produce a clot denser in structure and fibrin network ${ }^{[25]}$. PRF acts to release growth factors much more slowly as a result of both the use of a fibrin scaffold capable of trapping growth factors and releasing them slowly over time, as well as additionally harboring leukocytes, a cell type responsible for additional growth factor release ${ }^{[26]}$.

PRF fulfills the 3 main criteria by 1) acting simultaneously as a scaffold containing 2) living cells and 3) growth factors [27].

\subsubsection{Platelet Rich Liquid Fibrin}

In the absence of anticoagulants, platelet-rich fibrin forms a three-dimensional scaffold after 10-12 minutes of centrifugation at 200-700 $\mathrm{g}$ force. Lower centrifugation speeds and times (60 g for 3 minutes) have been used, to further optimize leukocyte numbers and subsequent growth factor release, the blood separates into a plasma-rich upper liquid layer without the use of anticoagulants, prior to fibrin formation, the injectable platelet-rich fibrin remains in its liquid consistency for approximately 10-15 minutes after centrifugation ${ }^{[28]}$. Platelet-rich liquid fibrin promotes the biological activity of various cell types, a higher concentration of platelets and leukocytes is obtained, which also offers the potential advantages of enhancing immune defense in inflammatory tissues with more growth factors available for release ${ }^{[27]}$. It is associated with a partial immune defense in response to a lipopolysaccharide (LPS) ${ }^{[29]}$ induced inflammatory condition. LPS is the major component of the bacterial membrane of gram-negative bacteria that contributes to pulpitis ${ }^{[30]}$. 


\subsubsection{Effect on Dental Pulp Cells}

Platelet Rich Fibrin enhance proliferation and migration of apical papilla stem cells. It activates extracellular signalregulated kinase signaling and extracellular signal-regulated kinase inhibitor attenuated platelet-rich fibrin-induced osteoodontogenesis of apical papilla stem cells [31]. PRF can stimulate osteoblast proliferation, cell proliferation can through positive regulation of phosphorylated extracellular signal-regulated protein kinase expression, suppress osteoclastogenesis by promoting osteoprotegerin secretion ${ }^{[32]}$. Enhances proliferation and differentiation of human dental pulp cells by positively regulating osteoprotegerin and alkaline phosphatase ${ }^{[33]}$. It forms an excellent matrix for bone growth, acting as an osteoconductive and osteoinductive substance ${ }^{[34]}$.

In a systematic review ${ }^{[35]}$, they concluded that Platelet Rich Fibrin causes an increase in proliferation, adhesion, migration and differentiation mainly in mesenchymal cells, and has antiinflammatory properties. It also shows a moderate but consistent ability to modulate the expression of target genes that activate different signaling pathways.

Platelet-rich liquid fibrin promoted a higher regeneration potential of dental pulp cells compared to traditional plateletrich plasma, besides it is associated with partial immune defense in response to a lipopolysaccharide-induced inflammatory condition and maintain a supportive regenerative capacity for the stimulation of odontoblastic differentiation and reparative dentin in dental pulp cells ${ }^{[29]}$.

Platelet Rich Fibrin, a second-generation platelet concentrate, releases growth factors more slowly, resulting in a fibrin network that traps leukocytes and platelets, immune cells and PRF cytokines act against infection. Lower centrifugation times allow PRF to be obtained in its liquid form during the first 15 minutes, which facilitates injection. Platelet-rich liquid fibrin has a higher concentration of leukocytes, which enhances immune defense in LPS-induced inflammation. PRF promotes superior mesenchymal stem cell proliferation and differentiation by upregulating osteoprotegerin and alkaline phosphatase, also has anti-inflammatory properties.

\subsection{Platelet Autologous Platelet Concentrates (PRP/PRF) vs. Blood Clot as Scaffolds in Regenerative Endodontics}

The healing pattern in cases of pulp endodontic regeneration with histological results has shown tissue repair but not regeneration of a new pulp-dentin complex with the same original architecture and biological function. Revascularization of immature necrotic teeth involves the intentional induction of bleeding from the periapical region and the formation of a blood clot, however, coagulation may be compromised if local anesthesia containing a vasoconstrictor such as adrenaline is used, and the content of growth factors in the blood clot is limited and unpredictable [36]

The use of different platelet concentrates is costly and less favorable for pediatric use compared to blood clot, but they can induce root growth and innervation with less possible risk of progressive root canal obliteration, they can also offer a longer and richer exposure to growth factors with possibly better support for cell differentiation and growth ${ }^{[37]}$. Platelet Rich Plasma may act as a successful scaffold for regenerative endodontic treatment, however, the treatment results were not significantly different from those of the conventional protocol using a blood clot as a scaffold ${ }^{[30]}$. Compared to a blood clot, Platelet Rich Plasma has shown a better clinical outcome in terms of periapical healing, apical closure and thickening of the root dentin wall10. Platelet Rich Fibrin due to the presence of leukocytes, cytokines and few lymphocytes, reduces infection and inflammation ${ }^{[39]}$.

Clinical efficacy of (PRP) and (PRF) versus Blood Clot Revascularization, for regeneration of immature permanent teeth, showed that apical closure may occur more frequently if PRF and PRP are used [40]. The healing response of the periapical lesion was $88.9 \%$ for blood clot, $100 \%$ for PRP, and $100 \%$ for PRF. A natural blood clot contains $94 \%$ red blood cells, 5\% platelets and 1\% white blood cells, while Platelet Rich Plasma contains $95 \%$ platelets ${ }^{[41]}$.

Histologically it has been demonstrated that in regenerative endodontics tissue repair is achieved, but not the creation of a new dentin-pulp complex. Autologous platelet concentrates have demonstrated superiority over the traditional blood clot protocol in periapical healing outcomes, root thickening and apical closure. In addition, PRF reduces infection and inflammation because it contains immune cells and cytokines.

\section{Conclusions}

Regenerative endodontic treatment is an option for immature teeth with pulp necrosis, and the use of autologous platelet concentrates as scaffolds has been suggested to enhance regenerative procedures. PRP has been shown to release growth factors within hours of placement. PRF is a secondgeneration platelet concentrate that releases growth factors more slowly, forming a network that traps leukocytes and platelets. Both demonstrate induction and proliferation of mesenchymal stem cells. Compared to blood clot, PRP and PRF show improved healing results, reducing infection and inflammation.

\section{References}

1. Kim S, Malek M, Sigurdsson A, Lin L, Kahler B. Regenerative endodontics: a review. Int Endod J 2018;51(12):1367-88.

2. Xu J, Gou L, Zhang P, Li H, Qiu S. Platelet-rich plasma and regenerative dentistry. Aust Dent J 2020;65(2):131142.

3. Yoshpe M, Einy S, Ruparel N, Lin S, Kaufman A. Regenerative Endodontics: A Potential Solution for External Root Resorption (Case Series). J Endod 2020;46(2):192-199.

4. Galler K, Widbiller M. Perspectives for cell-homing approaches to engineer dental pulp. J Endod 2017;43(9S):S40-S45.

5. Kontakiotis E, Filippatos C, Tzanetakis G, Agrafioti A. Regenerative Endodontic Therapy: A Data Analysis of Clinical Protocols. J Endod 2015;41(2):146-154.

6. Matoug-Elwerfelli M, Duggal M, Nazzal H, Esteves F, Raif E. A biocompatible decellularized pulp scaffold for regenerative endodontics. Int Endod J 2018;51(6):663-73.

7. Del Fabbro M, Lolato A, Bucchi C, Taschieri S, Weinstein R. Autologous Platelet Concentrates for Pulp and Dentin Regeneration: A Literature Review of Animal Studies. J Endod 2016;42(2):250-257.

8. ElSheshtawy A, Nazzal H, El Shahawy O, El Baz A, Ismail S, Kang J, et al. The effect of platelet-rich plasma as a scaffold in regeneration/revitalisation endodontics of immature permanent teeth assessed using 2-dimensional radiographs and Cone Beam Computed Tomography: A randomised controlled trial. Int Endod J 2020;53(7):905921.

9. Everts P, Onishi K, Jayaram P, Lana J, Mautner K. Platelet-Rich Plasma: New Performance Understandings 
and Therapeutic Considerations in 2020. Int J Mol Sci 2020;21(20):7794.

10. Gaviño J, Caviedes-Bucheli J, Manzanares M, Berástegui E, Martín B, Segura-Egea J et al. Use of Platelet-rich Plasma in Endodontic Procedures in Adults: Regeneration or Repair? A Report of 3 Cases with 5 Years of Follow-up. J Endod 2017;43(8):1294-1301.

11. Metlerska J, Fagogeni I, Nowicka A. Efficacy of Autologous Platelet Concentrates in Regenerative Endodontic Treatment: A Systematic Review of Human Studies. J Endod 2018;45(1):20-30.

12. He $\mathrm{L}$, Lin $\mathrm{Y}, \mathrm{Hu} \mathrm{X}$, Zhang $\mathrm{Y}, \mathrm{Wu} \mathrm{H}$. A comparative study of platelet-rich fibrin (PRF) and platelet-rich plasma (PRP) on the effect of proliferation and differentiation of rat osteoblasts in vitro. Oral Surg Oral Med Oral Pathol Oral Radiol Endod 2009;108(5):707713.

13. Hersant B, La Padula S, SidAhmed-Mezi M, Rodriguez A, Meningaud J. Use of platelet-rich plasma (PRP) in microsurgery. J Stomatol Oral Maxillofac Surg 2017;118(4):236-237.

14. Stambolsky C, Rodríguez-Benítez S, Gutiérrez-Pérez J, Torres-Lagares D, Martín-González J, Segura-Egea J. Histologic characterization of regenerated tissues after pulp revascularization of immature dog teeth with apical periodontitis using tri-antibiotic paste and platelet-rich plasma. Arch Oral Biol 2016;71:122-128.

15. Fujioka-Kobayashi M, Katagiri H, Kono M, Schaller B, Zhang Y, Sculean A, et al. Improved growth factor delivery and cellular activity using concentrated plateletrich fibrin (C-PRF) when compared with traditional injectable (i-PRF) protocols. Clin Oral Investig 2020;24(12):4373-4383.

16. Savovic J, Turner R, Mawdsley D, Jones H, Beynon R, Higgins $\mathrm{J}$, et al. Association Between Risk-of-Bias Assessments and Results of Randomized Trials in Cochrane Reviews: The ROBES Meta-Epidemiologic Study. Am J Epidemiol 2018;187(5):1113-1122.

17. Panda S, Mishra L, Arbildo-Vega HI, Lapinska B, Lukomska-Szymanska M, Khijmatgar $\mathrm{S}$, et al. Effectiveness of Autologous Platelet Concentrates in Management of Young Immature Necrotic Permanent Teeth-A Systematic Review and Meta-Analysis. Cells 2020;9(10):2241.

18. Torabinejad M, Turman M. Revitalization of Tooth with Necrotic Pulp and Open Apex by Using Platelet-rich Plasma: A Case Report. J Endod 2011;37(2):265-268.

19. Wang X, Zhang Y, Choukroun J, Ghanaati S, Miron R. Effects of an injectable platelet-rich fibrin on osteoblast behavior and bone tissue formation in comparison to platelet-rich plasma. Platelets 2018;29(1):48-55.

20. Roubelakis M, Trohatou O, Roubelakis A, Mili E, Kalaitzopoulos I, Papazoglou G, et al. Platelet-rich plasma (PRP) promotes fetal mesenchymal stem/stromal cell migration and wound healing process. Stem Cell Rev Rep 2014;10(3):417-428.

21. Fan Y, Perez K, Dym H. Clinical Uses of Platelet-Rich Fibrin in Oral and Maxillofacial Surgery. Dent Clin North Am 2020;64(2):291-303.

22. Zhou R, Wang Y, Chen Y, Chen S, Lyu H, Cai Z, et al. Radiographic, Histologic, and Biomechanical Evaluation of Combined Application of Platelet-rich Fibrin with Blood Clot in Regenerative Endodontics. J Endod 2017;43(12):2034-2040.

23. Lv H, Chen Y, Cai Z, Lei L, Zhang M, Zhou R, et al. The efficacy of platelet-rich fibrin as a scaffold in regenerative endodontic treatment: a retrospective controlled cohort study. BMC Oral Health 2018;18(1):139.

24. Dohan D, Choukroun J, Diss A, Dohan S, Dohan A, Mouhyi J, et al. Platelet-rich fibrin (PRF): a secondgeneration platelet concentrate. Part I: technological concepts and evolution. Oral Surg Oral Med Oral Pathol Oral Radiol Endod 2007;103(5):587-593.

25. Miron R, Xu H, Chai J, Wang J, Zheng S, Feng M, et al. Comparison of platelet-rich fibrin (PRF) produced using 3 commercially available centrifuges at both high $(\sim 700 \mathrm{~g})$ and low $(\sim 200 \mathrm{~g})$ relative centrifugation forces. Clin Oral Investig 2020;24(3):1171-1182.

26. Kobayashi E, Flückiger L, Fujioka-Kobayashi M, Sawada K, Sculean A, Schaller B, et al. Comparative release of growth factors from PRP, PRF, and advancedPRF. Clin Oral Investig 2016;20(9):2353-2360.

27. Miron R, Fujioka-Kobayashi M, Hernandez M, Kandalam U, Zhang Y, Ghanaati S, et al. Injectable platelet rich fibrin (i-PRF): opportunities in regenerative dentistry? Clin Oral Investig 2017;21(8):2619-2627.

28. Miron R, Zhang Y. Autologous liquid platelet rich fibrin: A novel drug delivery system. Acta Biomater 2018;15(75):35-51.

29. Chai J, Jin R, Yuan G, Kanter V, Miron R, Zhang Y. Effect of Liquid Platelet-rich Fibrin and Platelet-rich Plasma on the Regenerative Potential of Dental Pulp Cells Cultured under Inflammatory Conditions: A Comparative Analysis. J Endod 2019;45(8):1000-1008.

30. Rupf S, Kannengiesser S, Merte K, Pfister W, Sigusch B, Eschrich K. Comparison of profiles of key periodontal pathogens in periodontium and endodontium. Endod Dent Traumatol 2000;16(6):269-75.

31. Bi J, Liu Y, Liu X, Lei S, Chen X. Platelet-rich Fibrin Improves the Osteo-/Odontogenic Differentiation of Stem Cells from Apical Papilla via the Extracellular Signalregulated Protein Kinase Signaling Pathway. J Endod 2020;46(5):648-654.

32. Chang I, Tsai C, Chang Y. Platelet-rich fibrin modulates the expression of extracellular signal-regulated protein kinase and osteoprotegerin in human osteoblasts. J Biomed Mater Res A 2010;95(1):327-32.

33. Huang FM, Yang SF, Zhao JH, Chang YC. Platelet-rich fibrin increases proliferation and differentiation of human dental pulp cells. J Endod 2010;36(10):1628-32.

34. Goel S, Nawal R, Talwar S. Management of Dens Invaginatus Type II Associated with Immature Apex and Large Periradicular Lesion Using Platelet-rich Fibrin and Biodentine. J Endod 2017;43(10):1750-1755.

35. Strauss F, Nasirzade J, Kargarpoor Z, Stähli A, Gruber R. Effect of platelet-rich fibrin on cell proliferation, migration, differentiation, inflammation, and osteoclastogenesis: A systematic review of in vitro studies. Clin Oral Investig 2020;24(2):569-584.

36. Lolato A, Bucchi C, Taschieri S, Kabbaney A, Fabbro M. Platelet concentrates for revitalization of immature necrotic teeth: a systematic review of the clinical studies. Platelets. 2016;27(5):383-392.

37. Ulusoy A, Turedi I, Cimen M, Cehreli Z. Evaluation of Blood Clot, Platelet-rich Plasma, Platelet-rich Fibrin, and Platelet Pellet as Scaffolds in Regenerative Endodontic Treatment: A Prospective Randomized Trial. J Endod 2019; 45(5):560-566.

38. Alagl A, Bedi S, Hassan K, AlHumaid J. Use of platelet- 
rich plasma for regeneration in non-vital immature permanent teeth: Clinical and cone-beam computed tomography evaluation. J Int Med Res 2017;45(2):583593.

39. Bakhtiar H, Esmaeili S, Fakhr Tabatabayi S, Ellini MR, Nekoofar MH, Dummer PM. Second-generation Platelet Concentrate (Platelet-rich Fibrin) as a Scaffold in Regenerative Endodontics: A Case Series. J Endod 2017;43(3):401-408.

40. Murray P. Platelet-Rich Plasma and Platelet-Rich Fibrin Can Induce Apical Closure More Frequently Than BloodClot Revascularization for the Regeneration of Immature Permanent Teeth: A Meta-Analysis of Clinical Efficacy. Front Bioeng Biotechnol 2018;11(6):139.

41. Feigin K, Shope B. Use of Platelet-Rich Plasma and Platelet-Rich Fibrin in Dentistry and Oral Surgery: Introduction and Review of the Literature. J Vet Dent 2019;36(2):109-123. 